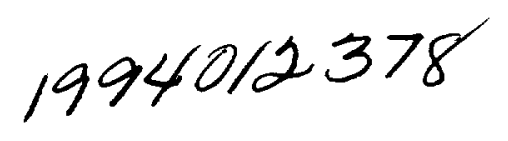

$-60.24$

\title{
EFFECT OF TOW ALIGNMENT ON THE MECHANICAL PERFORMANCE OF 3D WOVEN TEXTILE COMPOSITES
}

\author{
Timothy L. Norman \\ Department of Mechanical and Aerospace Engineering, \\ West Virginia University, Morgantown, WV 26506 \\ Patti Allison, Jack W. Baldwin, Brian K. Gracias \\ General Electric Aircraft Engines, Cincinnati, OH \\ Dave Seesdorf \\ Westinghouse, Pittsburgh, PA
}

\begin{abstract}
Three-dimensional (3D) woven preforms are currently being considered for use as primary structural components. Lack of technology to properly manufacture, characterize and predict mechanical properties and predict damage mechanisms leading to failure are problems facing designers of textile composite materials. In this study, two material systems with identical specifications but different manufacturing approaches are investigated. One manufacturing approach resulted in an irregular (nonuniform) preform geometry. The other approach yielded the expected preform geometry (uniform). The objectives of this study are to compare the mechanical properties of the uniform and nonuniform angle interlock 3D weave constructions. The effect of adding layers of laminated tape to the outer surfaces of the textile preform is also examined. Damage mechanisms are investigated and test methods are evaluated.
\end{abstract}

\section{INTRODUCTION}

Multidimensional textile composites are widely becoming an increasingly popular alternative to traditional laminated composite materials in that they may offer distinct advantages in strength, cost, manufacturability, and damage resistance. These materials, however, are relatively new and possess a number of fiber, resin, and angular orientation possibilities. For these reasons, there is a great need to characterize their behavior. 3D composites pose a viable alternative to more conventional materials such as titanium and aluminum for lightweight, high strength designs with a requirement for a high resistance to impact damage.

Few investigations have been conducted to determine damage mechanisms in 3D woven textile composites, although recent studies have been conducted on damage of braided textile 
composite materials (currently not published). Reference 1 investigated damage development and manufacturing of braided composites. Their study investigated mechanics of materials and manufacturing of 2D, 2D triaxial and 3D braid patterns. The structural performance was evaluated through an extensive mechanical test program. Of particular interest was the characterization of the mechanical response and possible failure mechanisms of braided composite material systems, and the effect of different fiber architectures on mechanical behavior. Open hole tension, unnotched tension and compression, compression after impact, inplane shear, transverse shear, transverse tension and bearing tests were conducted. The effect of unit cell size on strain gage strain was also investigated. The failure mechanism of the fully braided composite loaded in tension was described as shear-out which occurred along tow boundaries in the following repeating sequence: 1) braided tow failure, 2) cracks forming at the broken tow boundary and propagating until a braided cross-over point, 3) failure of an intersecting tow at the cross-over point, 4) cracks forming at the intersection broken tow boundary and propagation until the next braided cross-over point. Failure of triaxially braided composites was observed as starting as longitudinal tow failure, followed by load redistribution into the braided tows, followed by the shear-out failure described above.

Many interesting findings were presented by reference 2 after testing the impact properties of 3D braided graphite/epoxy composites. 3D braided composites show excellent impact insensitivity as compared to laminated composites. After low velocity impact testing, 3D braided composites exhibited "surface matrix cracking in resin pockets, separation of fiber tows, fiber tow breaking, and debonding of matrix and fiber filament within broken fiber tow." In tests of reference 2, most of the broken fiber bundles were found in "fiber crimp areas" (areas where the weaving of the yarns made bends into or away from an interface). From these observations, it was hypothesized that the existence of small fiber-to-fiber interfaces in 3D braids would cause "inter-fiber-tow stresses" to develop. In this instance, fiber tow breakage was considered to be much more detrimental than fiber tow separation.

The diversity of the woven preform makes the composite unique in that there is no real layer of lamination as in traditional laminated composites. It is the $45^{\circ}$ fibers that actually resist the interlaminar shear forces that nornally cause parallel planes to separate within a material (ref. 3). Advantages of woven textile composites are an increase in impact properties due to the weave's ability to resist delamination and shear cracking (ref. 4) and the overall composite's increased energy absorption characteristics (ref. 5). As a consequence of these properties, there is a gain in the composite's residual tensile and compressive strength (ref. 4) with a loss in inplane strength and stiffness.

In this study, two material systems with identical specifications but different manufacturing approaches are investigated. One manufacturing approach resulted in an irregular (nonuniform) preform geometry. The other approach yielded the expected preform geometry (uniform). The objectives of this study are to compare the mechanical properties of the uniform and nonuniform angle interlock 3D weave constructions. The effect of adding layers of laminated tape to the outer surfaces of the textile preform is also examined. Damage mechanisms are investigated and test methods are evaluated. 


\section{MATERIAL ARCHITECTURE}

Four different material architectures are used in this study and are identified as: uniform, uniform with tape, nonuniform, nonuniform with tape. Cross-sectional views of the uniform and nonuniform preforms are shown in figures 1 and 2, respectively.

The 3D woven preform was designed to provide exceptional strength in the length direction and to enhance through the thickness resistance to delamination normally present in laminated composites. To provide that strength, the preform was designed to have $50 \%$ fibers in the $\mathrm{X}$ direction (called $0^{\circ}$ ), $30 \%$ fibers in the $\mathrm{Y}$ direction (called $90^{\circ}$ ), and $20 \%$ fibers in the out-of-plane $Z$ direction (called $\pm 45^{\circ}$ ). Calculations showed actual fiber percentages in a random 0 tensile specimen section from the uniform preform were found to be $35 \% 0^{\circ}$ fibers, 35 $\% 90^{\circ}$ fibers, and $14 \% \pm 45^{\circ}$ fibers, by using a weave consisting of $0^{\circ}$ and $90^{\circ}$ fibers, with $\pm 45^{\circ}$ fibers forming an "angle interlock weave configuration" (ref. 6) acting to stitch the preform together. No information is available to date for actual fiber percentages for nonuniform preform.

Since this architecture is 3-D with many interlocking weaves of tows, the structure is difficult to visualize. As a result, determining damage mechanisms and damage progression of the composite requires careful evaluation of many planes of view. By nature, the 3-D weave configuration of the preform causes there to be a continuously varying cross-section. This contradicts the typical convention of laminated composites where there is a constant material cross-section, making material sectioning a matter of personal preference. The complexity of this 3-D textile structure necessitates a well planned method of evaluation. The material evaluation technique/protocol created was based on the idealized planes of view shown in figures $1 \mathrm{~b}$ and $2 \mathrm{~b}$.

\section{EXPERIMENTAL PROCEDURE}

Specimens were machined from four graphite/epoxy panels, two 12 " $\times 10$ " 0.50 " and two 12" x 10 " by 0.75 ". The two 0.75 " thick panels contained a co-cured tape layup on both outer surfaces of the panel. The specimens were machined for the following tests: knight compression, $0^{\circ}$ interlaminar shear, $90^{\circ}$ interlaminar shear, flatwise tension, $0^{\circ}$ tension, $90^{\circ}$ tension and $0^{\circ}$ flexural. Flexural tests were not conducted for specimens with tape. Testing was conducted by Delsen Testing Laboratories, Inc. (Glendale, CA 91201-3011).

Knight compression tests were conducted according to ASTM D 695-89. The specimens were tested such that the load was applied in the $\mathrm{Z}$ (out-of-plane) direction. Modulus was determined from the initial linear portion of the load-strain curve. Interlaminar shear strength specimens were tested in accordance with the procedures outlined in ASTM D 2344-89. Specimens were machined to a span to a depth ratio of $4: 1$. Flatwise tension specimens were tested in accordance with the procedures outlined in ASTM C 297-66(88). Strain was measured using micromeasurements strain gage CEA-06-125-UW-350. Specimens were tested at a rate of 0.005 inches/minute. Ultimate strength, modulus and strain to failure were recorded. Modulus was determined from the initial portion of the load-strain curve. Tensile properties for $0^{\circ}$ and $90^{\circ}$ specimens were tested in accordance with procedures outlined in ASTM 639-89, using a 
type II tensile specimen configuration and a Micro-Measurements CEA-06-125UW-350 strain gage. Ultimate strength, modulus and strain to failure were recorded. Flexural tests were conducted according to ASTM D 790-86 method II, procedure A. A span of 7.5 inches was used to conduct the test. Modulus was determined from the initial linear portion of the load deflection curve. Resent studies have shown that unit cell size should be considered when selecting strain gage size. Unit cell size was not a consideration in the present study.

After testing, macro- and micro-scopic inspections were conducted. In the macroscopic examination stage, inspection and photographs of the tested specimens were performed under low power of a dissecting microscope. Following macroscopic inspections, specimens were sectioned and polished for microscopic inspection. An Olympus SZH research dissecting microscope was used to obtain photomicrographs of the polished cross-sections.

\section{RESULTS}

\section{Pretest Conditions}

Specimens of uniform construction with tape were used to investigate pre-test characteristics. Tows appeared to be well bonded to matrix but were present with microcracks (figure 3). These microcracks were also found lying in resin pockets. Microcracks are not clearly observed in the photo because of the epoxy used when making the mold of the specimen. This emphasizes the importance of using a radioluscent filler in the epoxy for materials with voids and cracks in resin filled areas. Cracking was not restricted to a single fiber direction or plane of view. A small resin rich layer between coincident fiber bundles within the same tow can also be recognized in the figure.

The exact cause of these pre-existing cracks or their effect on material strength and damage resistance is unknown, but stress fractures in fibers during the weaving process and shrinkage during cure are viable explanations for their origination. This problem was corrected in subsequent material preforms.

\section{Strength and Stiffness}

\section{Tension}

Figures 4 and 5 show tensile strength and stiffness, respectively, for $0^{\circ}$ and $90^{\circ}$ uniform, uniform with tape and nonuniform specimens. The data shown in the figures has been normalized to the $0^{\circ}$ tensile properties. Both $0^{\circ}$ and $90^{\circ}$ specimens of figure 4 show reductions in strength for the nonuniform preform. Uniform specimens with tape resulted in further reductions in strength. Testing of nonuniform preform with tape was discontinued due to the applied gripping force necessary to prevent slippage of the specimen. This high grip force caused out-of-plane compression failure, which may have resulted in strength reductions. Stiffness reductions for nonuniform specimens are also observed in $90^{\circ}$ specimens. Nonuniform specimens, however, exhibited a small increase in stiffness of approximately $5 \%$. Stress-strain curves for 0 and 90 degree uniform specimens are shown in figures 6 and 7, respectively. Uniform and nonuniform specimens exhibited similar behavior: a region of linear elastic behavior followed by a region of nonlinear behavior. Average $0^{\circ}$ uniform strain at failure was higher than nonuniform; however, average $90^{\circ}$ uniform strain at failure was higher than nonuniform strain at failure. 


\section{Flatwise Tension}

Figure 8 shows a comparison of strength and stiffness for flatwise tension uniform and nonuniform specimens with and without tape. Results of this figure show that through thickness strength and stiffness is higher for nonuniform specimens than for uniform specimens: out-of-plane strength was only slightly higher but stiffness was significantly higher. Strength and stiffness decrease when tape is added to uniform specimens. Tape decreased stiffness of uniform specimens but increased strength of nonuniform specimens.

\section{Interlaminar Shear and $0^{\circ}$ Flexure}

Results from interlaminar shear strength tests are shown in figure 9. These results show that interlaminar shear strength and stiffness of $0^{\circ}$ and $90^{\circ}$ uniform specimens was higher than that of nonuniform specimens. No significant differences, were found between nonuniform specimens with or without tape. Notable decreases were observed for uniform specimens with tape. $0^{\circ}$ flexure test results (fig. 10) show that stiffness and strength was significantly higher for uniform than for nonuniform specimens.

\section{Knight Block Compression}

Knight block compression strength and stiffness of uniform specimens was higher than nonuniform specimens (fig. 11). Strength and stiffness of uniform specimens with tape increased but decreased for nonuniform specimens with tape.

\section{Damage Mechanisms}

\section{Tension}

A pronounced "arrowhead" failure pattern became characteristic of the through thickness damage in the $0^{\circ}$ tensile specimens (fig. 12). Tow separation occurred between adjacent $90^{\circ}$ tows along the shear plane that runs along the 0 direction created by the interlocking geometry of the $\pm 45^{\circ}$ architecture. The direction of the fracture reverses at the midplane of the composite where the $\pm 45^{\circ}$ tows cross. The $90^{\circ}$ specimens failed nearly perpendicular to the loading direction (fig. 13). All specimens exhibited matrix cracking, tow rupture and tow pullout at the fracture site. Intra-tow fracture occurred in tows perpendicular to the loading direction. Widespread matrix cracking is present at the fracture site and at locations remote from the fracture site. Figure 14 shows a photomicrograph of a $90^{\circ}$ specimen after loading that exhibits matrix cracking, fiber breakage and intra-tow failure. Figure 15 shows a crack propagating through $0^{\circ}$ and $90^{\circ}$ fibers and fiber debonding.

\section{Flatwise tension}

Top ply failure and bond failure between the test specimen and the end tape were commonly observed for specimens without tape. For specimens with tape, top ply failure in the composite and delamination failure between the tape and the textile composite were commonly observed. Delamination of the top ply occurred by crack bridging with bridging traction supplied by the through thickness weave profile at the interface. Cracking was also observed through the thickness in the resin along the transverse and longitudinal tows. 
Interlaminar Shear and Flexural Test

Delamination at the resin interface between the tape and textile was commonly observed in uniform and nonuniform specimens with tape. Cracking is observed in $0^{\circ}$ uniform and nonuniform flexural test specimens (fig. 16) propagating from load application point and spreading through the thickness following the $\pm 45^{\circ}$ tow by crack bridging with the bridging traction supplied by the through thickness yarns. The transverse shear cracks in $90^{\circ}$ specimens are oriented radially from the load application point, and propagate in a staircase fashion similar to damage observed in laminated composites subjected to transverse impact loading.

\section{Knight Block Compression}

Compression failure occurred with extensive delaminations between tows and matrix. A $45^{\circ}$ shear failure on the $90^{\circ}$ cross-section was also observed. Damage was confined primarily to the textile material; little damage occurred in the composite laminate tape. Uniform specimens broke into two pieces at failure whereas nonuniform specimens remained intact. Decreased compliance of the nonuniform specimens may have caused these failure differences.

\section{SUMMARY}

\section{Strength and Stiffness}

In general, strength and stiffness decreased with nonuniformity. There were three exceptions:

o Flatwise tension strength and stiffness increased

o Small increase in $0^{\circ}$ tensile modulus

o No significant effect on out-of-plane strength

Tensile stress-strain curves of both materials showed a linear portion followed by nonlinear region until failure. $0^{\circ}$ uniform specimens exhibited higher strain to failure than nonuniform. $90^{\circ}$ nonuniform exhibited higher strain to failure than uniform.

\section{Effect of Tape}

In-Plane and Shear Loading

- Tape reduced strength

- Small effect on stiffness (In-plane only)

\section{Out-of-Plane Loading}

- Tape increased nonuniform strength (T\&C)

- Tape reduced uniform strength (C)

- Tape reduced uniform and nonuniform stiffness (T)

\section{Damage Mechanisms}

Pretest Conditions

o Cracks in neat resin pockets

o Intra-tow resin line (consolidation)

o Cracks in tows 
General Failure Mechanisms

In-plane loading - matrix cracking, tow rupture and tow pullout.

Flatwise tension - top ply delamination, transverse and longitudinal tow/matrix interface cracking, end tap debonding, tape debonding.

Interlaminar Shear - transverse cracking along through thickness weave emanating from load application point, tape separation at interface

Knight Block Compression - $45^{\circ}$ shear failure in $90^{\circ}$ section, uniform specimens broke into pieces whereas nonuniform remained intact.

\section{Evaluation of Test Methods}

Some tests developed for isotropic materials do not properly evaluate material performance. High grip pressure required in tensile tests caused delamination and fracture. Out-of-plane tests resulted in end tab failure and delamination of the tape. The single most complicating factor of all tests is the lack of understanding as to what constitutes failure. Most textile composites continue to carry load after "fracture". Textile composites are more difficult to test and draw conclusions from to evaluate the quality of the composite.

\section{Damage Progression}

It is likely that matrix cracking in a resin pocket on fiber matrix interface is the first form of damage found in the textile composite. Continued loading causes crack to propagate to neighboring tows, which causes high stress concentrations at the interface. With increased loading, tow rupture occurs. The crack continues to propagate along tow/resin interface, causing the crack formation to follow a pattern created by the geometry of the 3-D architecture, i.e. weave angle.

\section{RECOMMENDATIONS}

Most test methodology used on textile composite materials was developed for isotropic materials. Test results developed for isotropic materials may not necessarily provide an accurate assessment of 3D textile preforms. Therefore, there is a great need to develop new test methodology that can truly evaluate the performance of the textile composite.

A second recommendation would be to establish what constitutes failure in textile composite materials. Clearly, there are different levels of failure. For isotropic materials, failure is easily identified, usually resulting in catastrophic fracture, leaving the specimen virtually incapable of carrying load. Laminated composites are able to carry load even after significant delaminations and transverse shear cracking, but load carrying capability quickly diminishes with fiber breaks. Textile composites continue to carry load after noticeable fracture. Significant deformation can develop without catastrophic failure. Despite this quality, textile 
composites are often evaluated with the same criteria as isotropic or laminated composite criteria. This interpretation of test data will undoubtably present a false picture of textile composites. Failure criteria for textile composite materials needs to be established.

A third recommendation is to investigate the effects of architecture on damage patterns. Crack movement might possibly be anticipated with a preform being woven so as to inhibit a continual snowballing energy buildup in the crack front along the tow. Increasing the resistance to crack growth (fracture toughness) of the matrix might prolong crack initiation. Additionally, decreasing the size and number of the neat resin pockets might delay or eliminate the onset of crack initiation. As evidenced by the variation in damage in the $0^{\circ}$ and $90^{\circ}$ tensile test specimens, architecture does have a direct effect on the way in which the textile composite fails. Design for failure might play an important role in the use of textile composites.

\section{ACKNOWLEDGEMENT}

This work was supported by General Electric Aircraft Engines.

\section{REFERENCES}

1. Fedro, Mark J. and Wilden, Kurtis: Characterization and Manufacture of Braided Composites for Large Commercial Aircraft Structures. Ninth DOD/NASA/FAA Conference on Fibrous Composites in Structural Design, November 4-7, Lake Tahoe, NV, 1991.

2. Gong, J.C. and Sankar, B.V.: Impact Properties of Three Dimensional Braided Graphite/Epoxy Composite. Journal of Composite Materials, Vol. 25, June, 1991.

3. Mohamed, Mansour H.: Three-Dimensional Textiles. American Scientist, Vol. 78, November-December, 1990, p. 530.

4. Bishop, Sarah M. : Strength and Failure of Woven Carbon-Fiber Reinforced Plastics for High Performance Applications. Textile Structural Composites, Composite Materials Series, 3, 1989 , pp. 173-207.

5. Naik, N.K., Shembekar, P.S., and Verma, M.K. : On the Influence of Stacking Sequence on Notch Sensitivity of Fabric Laminates. Journal of Composite Materials, Vol. 24, August, 1990 , p. 838.

6. Zawislak, S.P. and Maiden, J.R.: Advanced Weaving Concepts for Complex Structural Preforms. Fiber-Tex, NASA Conference Publication 3038, 1988, p. 91. 


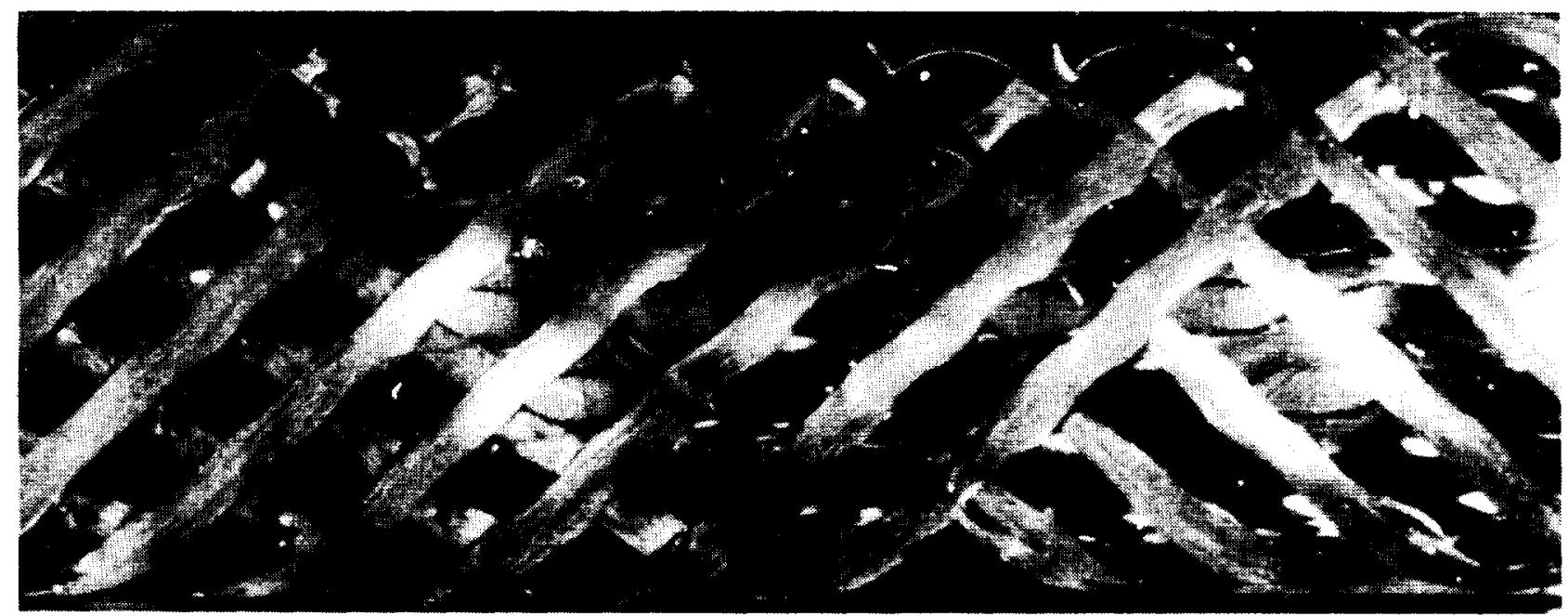

(a)
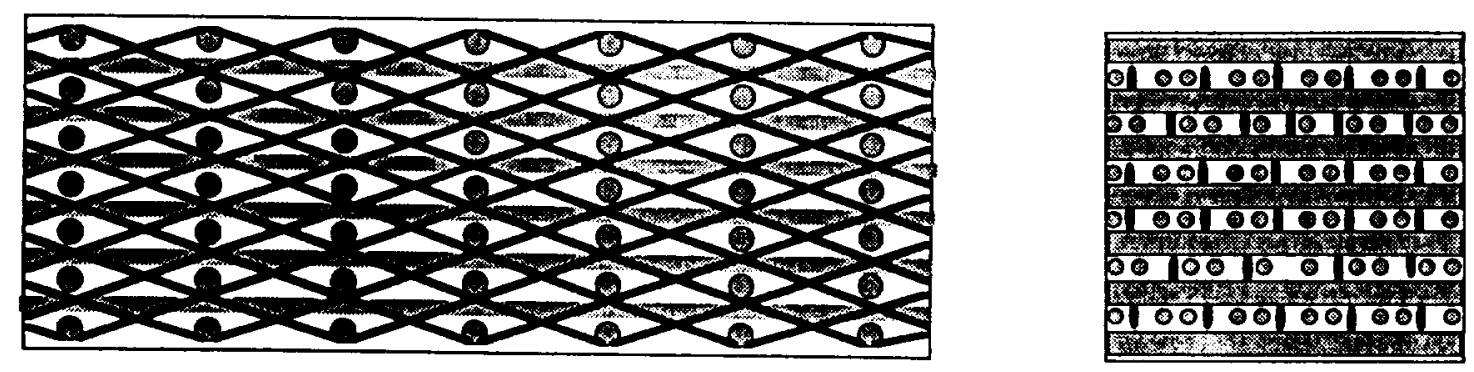

(b)

Figure 1. Cross-sectional view of the uniform construction shown as a) photomicrograph of $90^{\circ}$ view, and b) computer drawing of $90^{\circ}$ and $0^{\circ}$ views. 


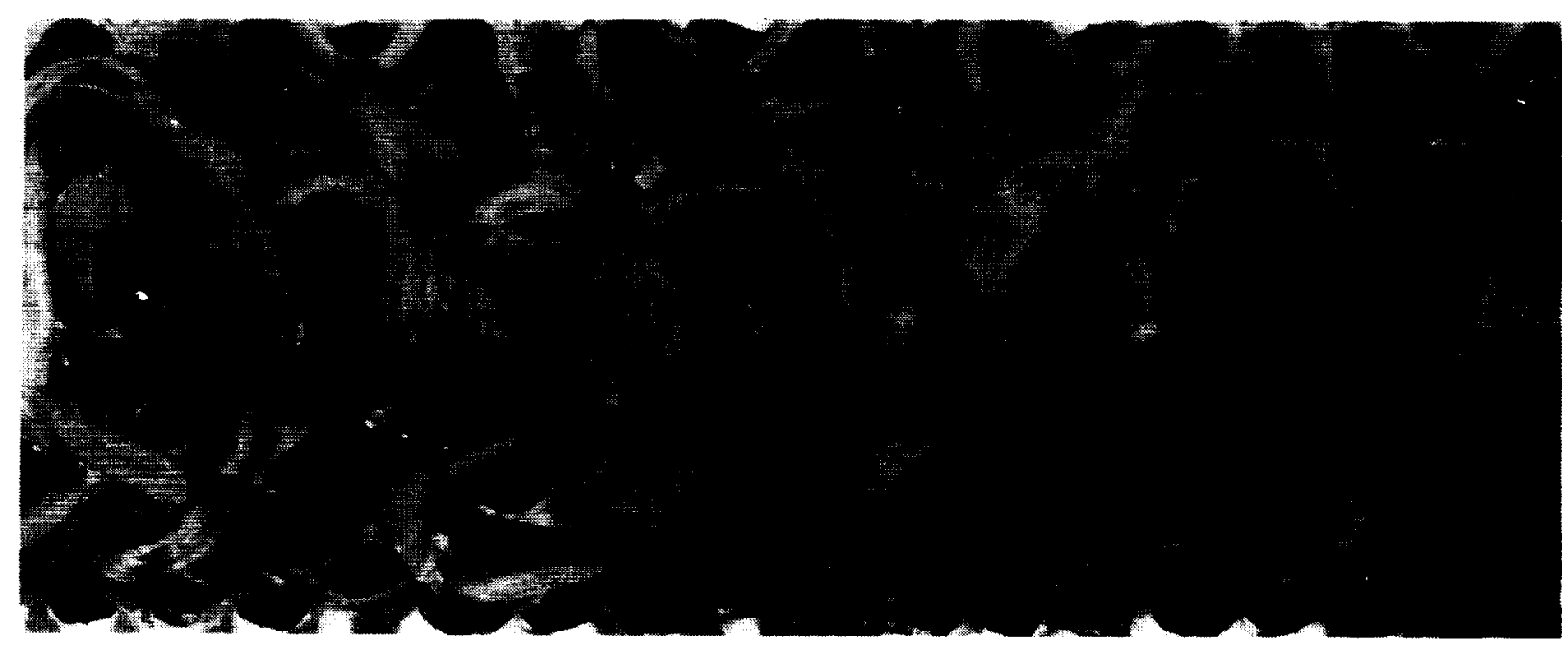

(a)
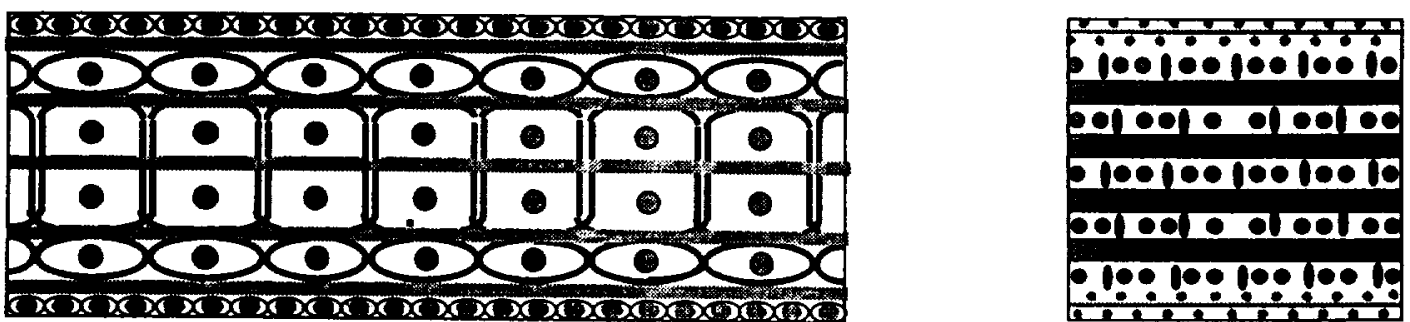

(b)

Figure 2. Cross-sectional view of the nonuniform construction shown as a) photomicrograph of $90^{\circ}$ view, and b) computer drawing of $90^{\circ}$ and $0^{\circ}$ views. 


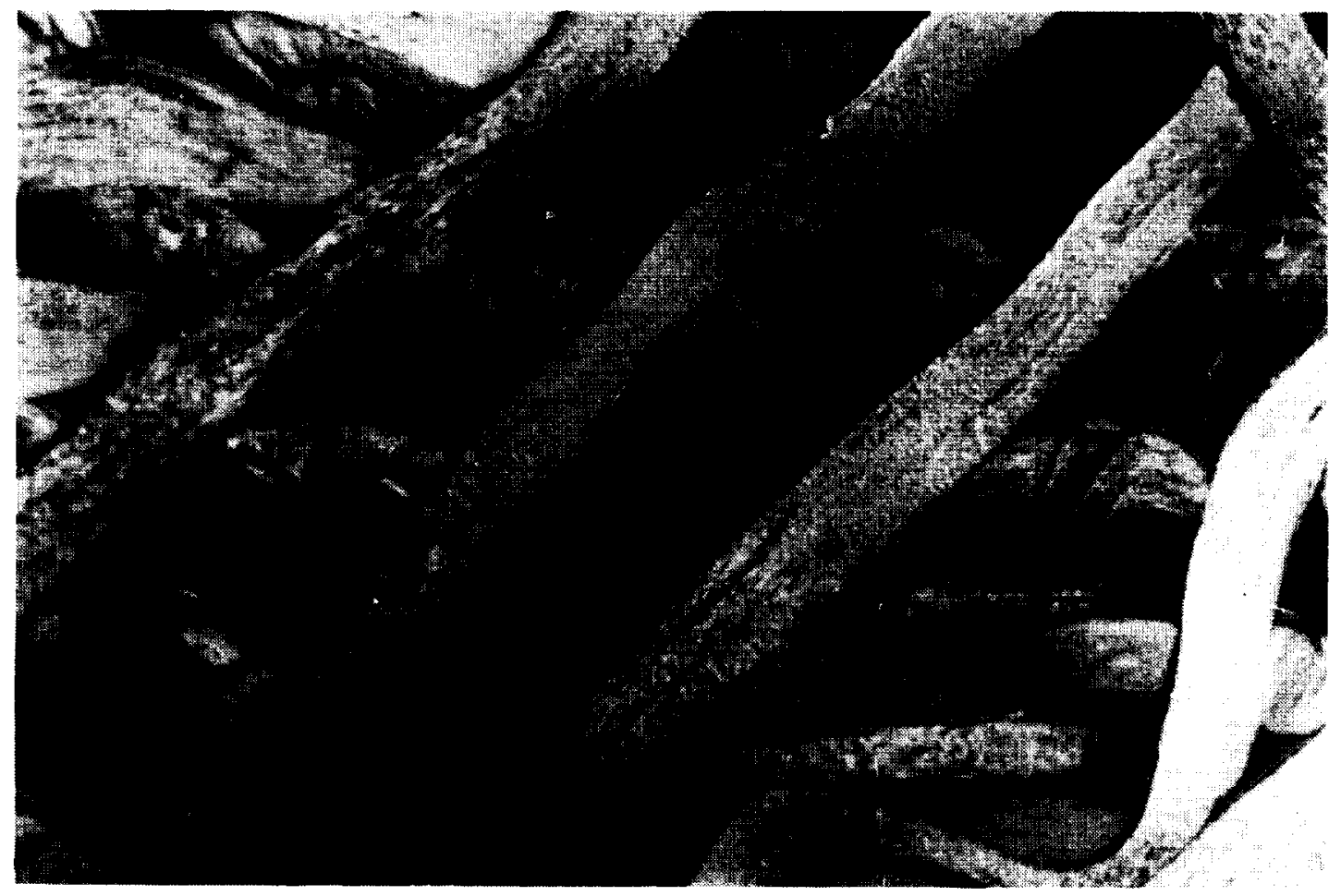

Figure 3. Photomicrograph of $90^{\circ}$ cross-sectional view of a uniform construction showing cracking in tows found in pretest specimens.

Tensile Strength

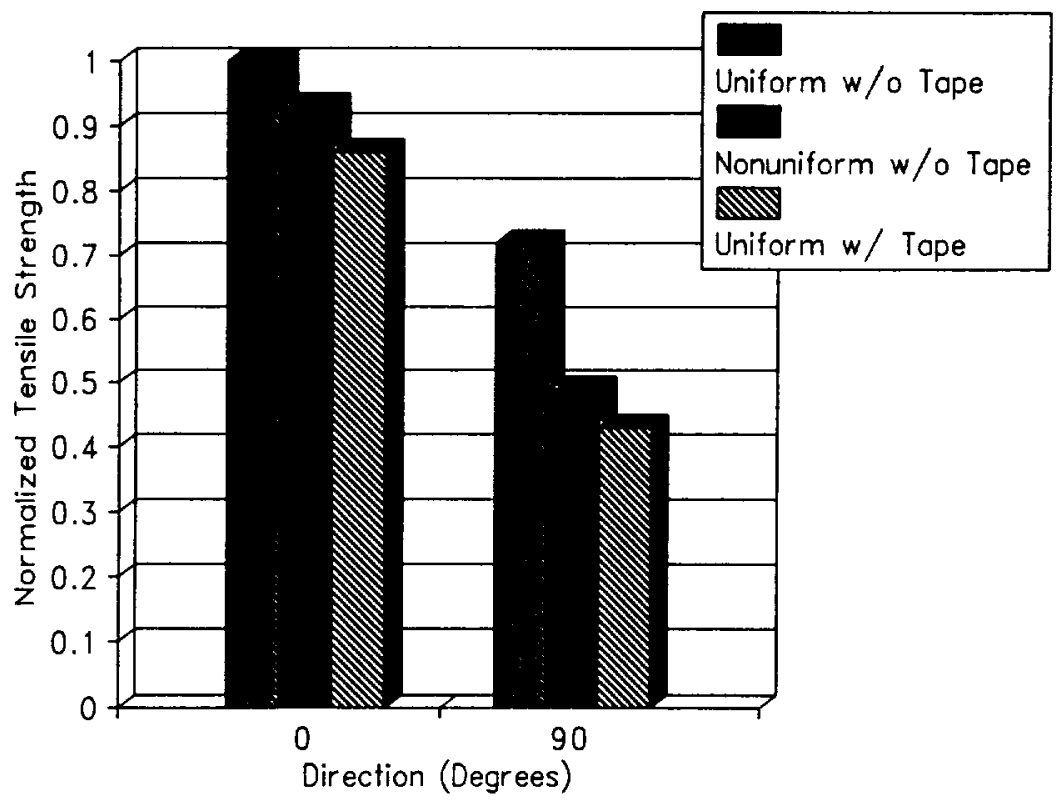

Figure 4. Tensile strength of uniform and nonuniform specimens. 


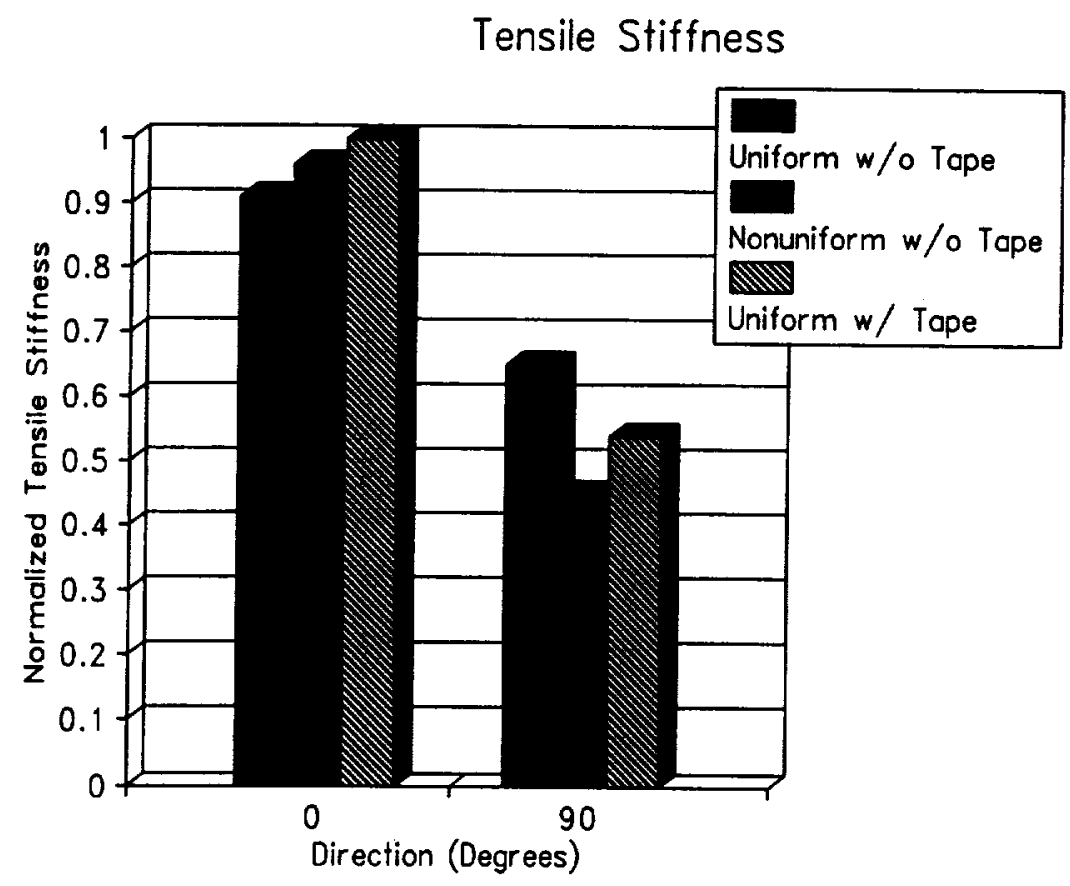

Figure 5. Tensile stiffness of uniform and nonuniform specimens.

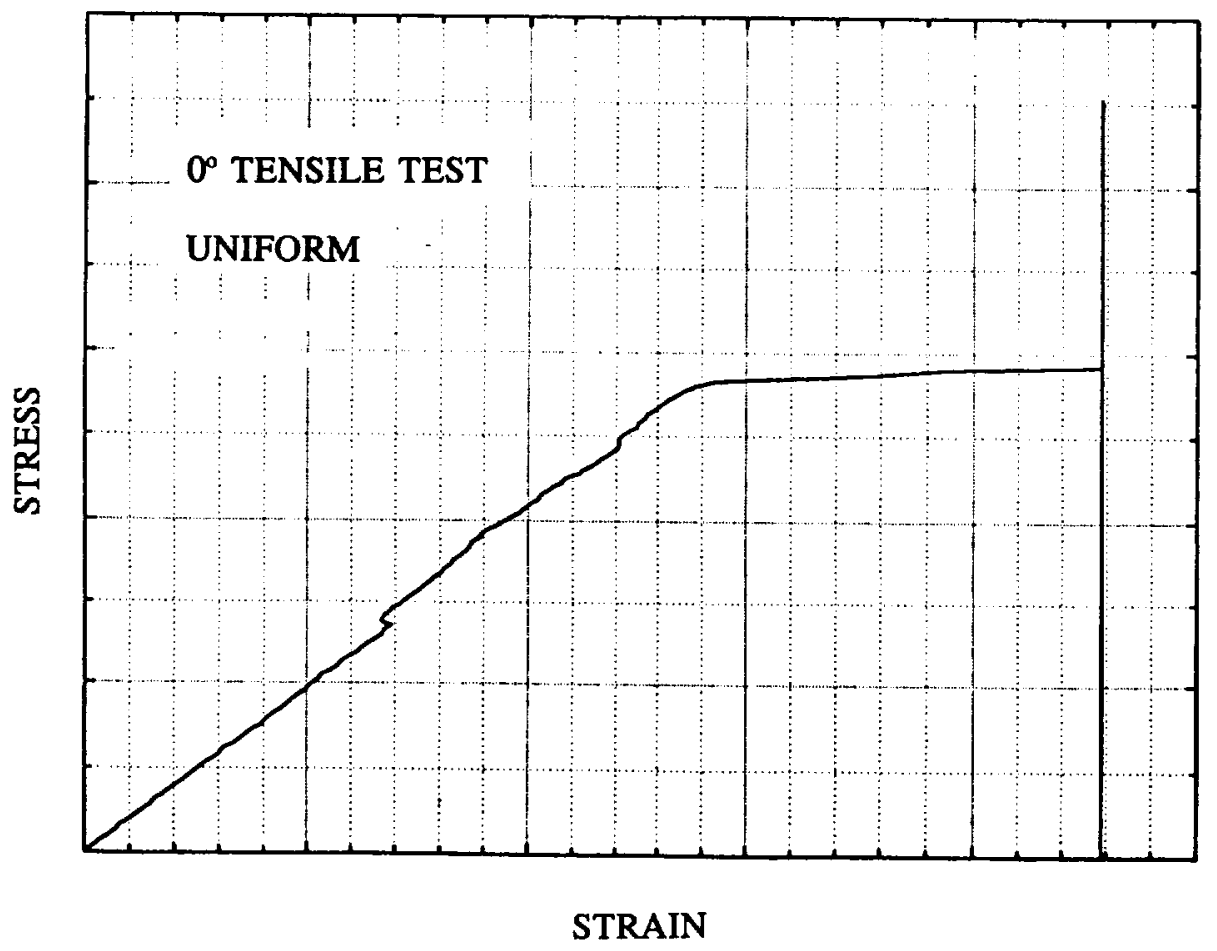

Figure 6. Stress-strain curve of $0^{\circ}$ uniform specimen under tensile loading. 


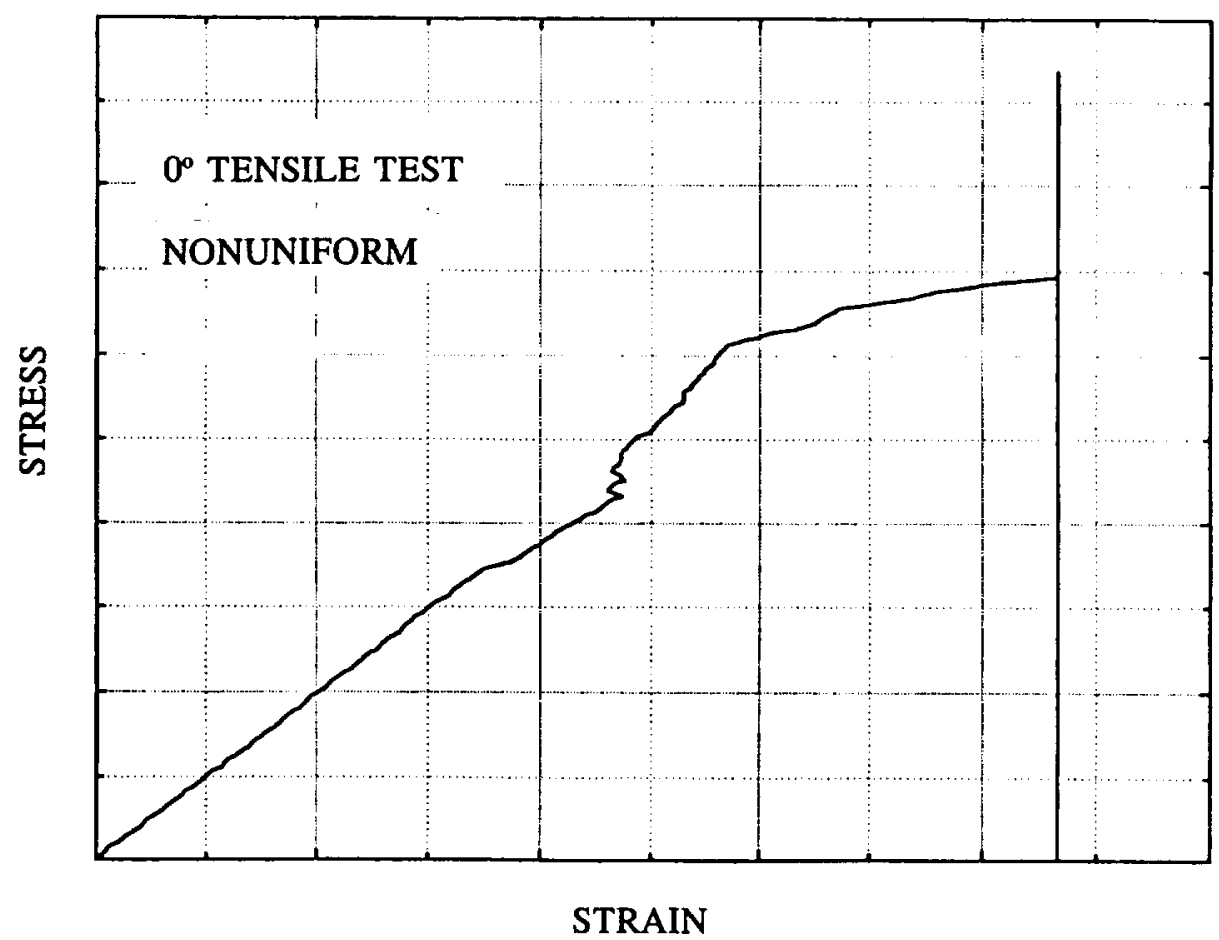

Figure 7. Stress-strain curve of $0^{\circ}$ nonuniform specimen under tensile loading.

Flatwise Tensile Strength and Stiffness

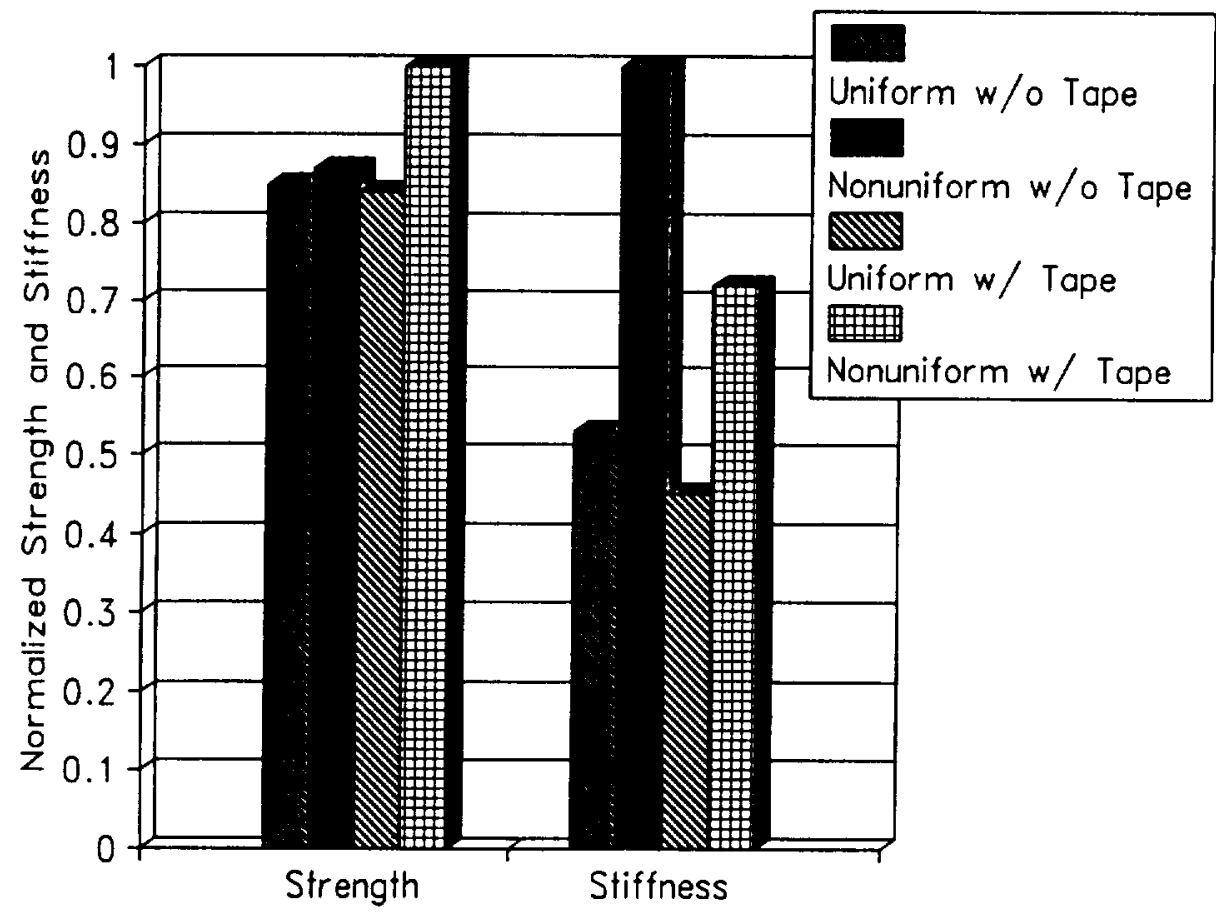

Figure 8. Strength and stiffness of uniform and nonuniform flatwise tension specimens. 


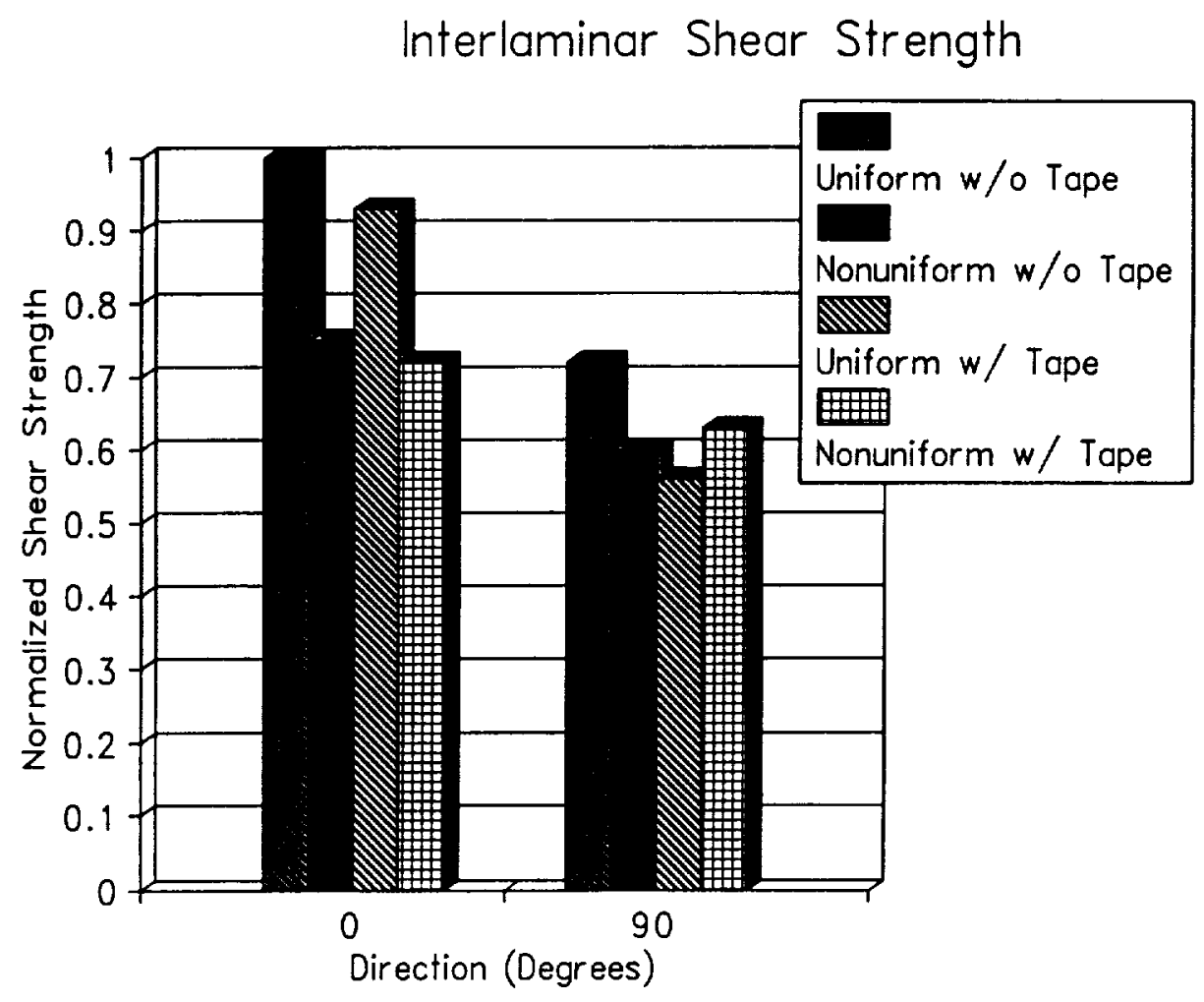

Figure 9. Interlaminar shear strength for uniform and nonuniform specimens.

Flexural Strength and Stiffness

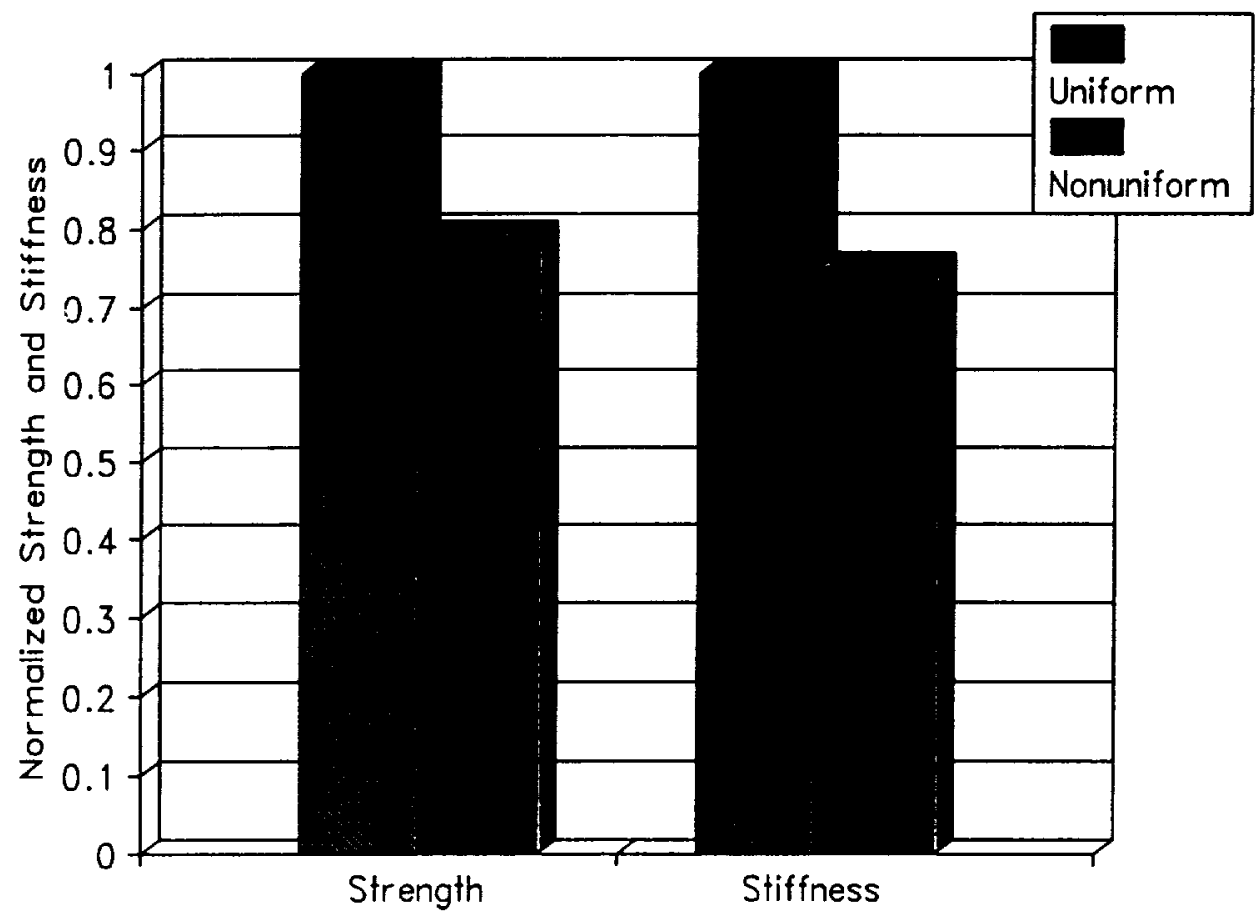

Figure 10. Flexural strength and stiffness for uniform and nonuniform specimens. 
Knight Block Strength and Stiffness

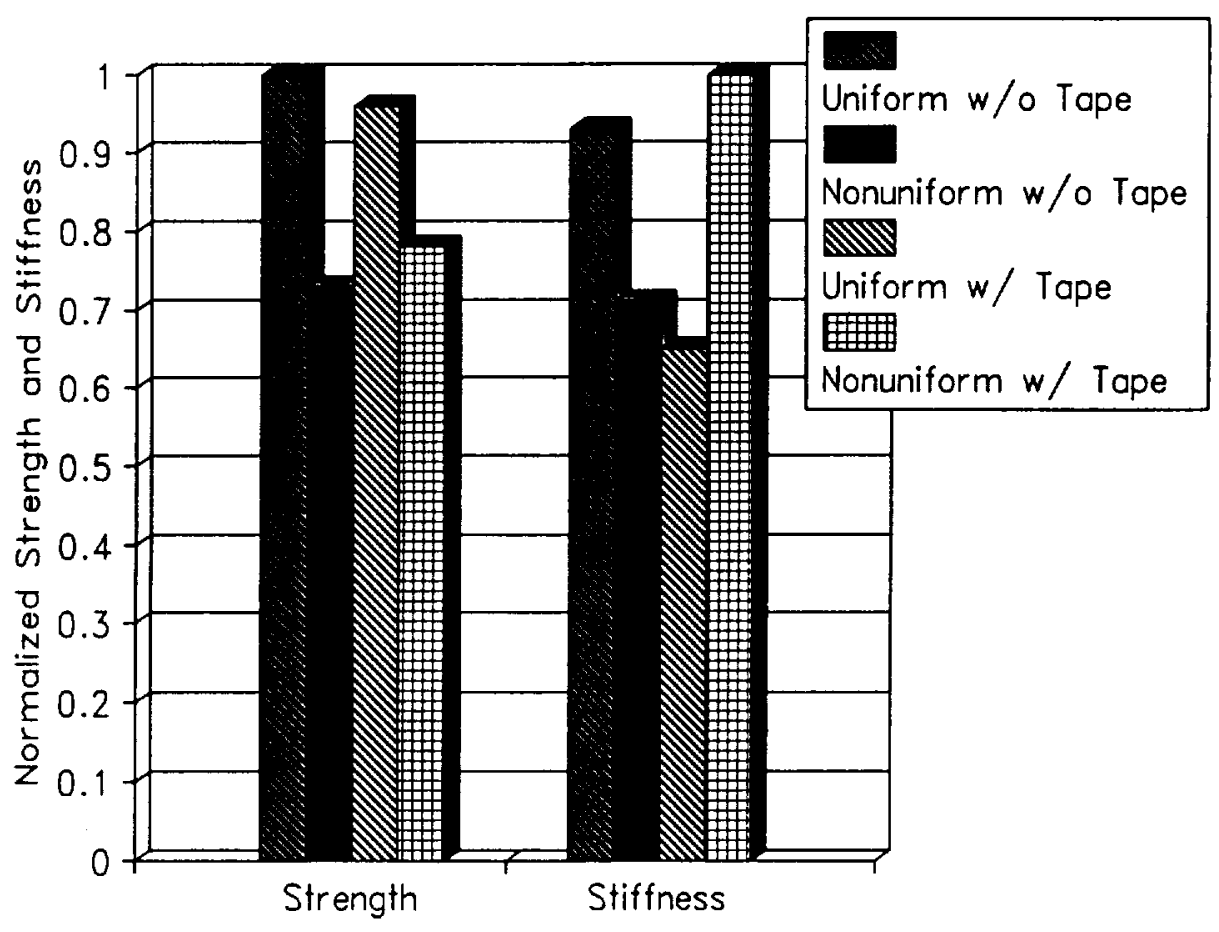

Figure 11. Knight block strength and stiffness for uniform and nonuniform specimens.

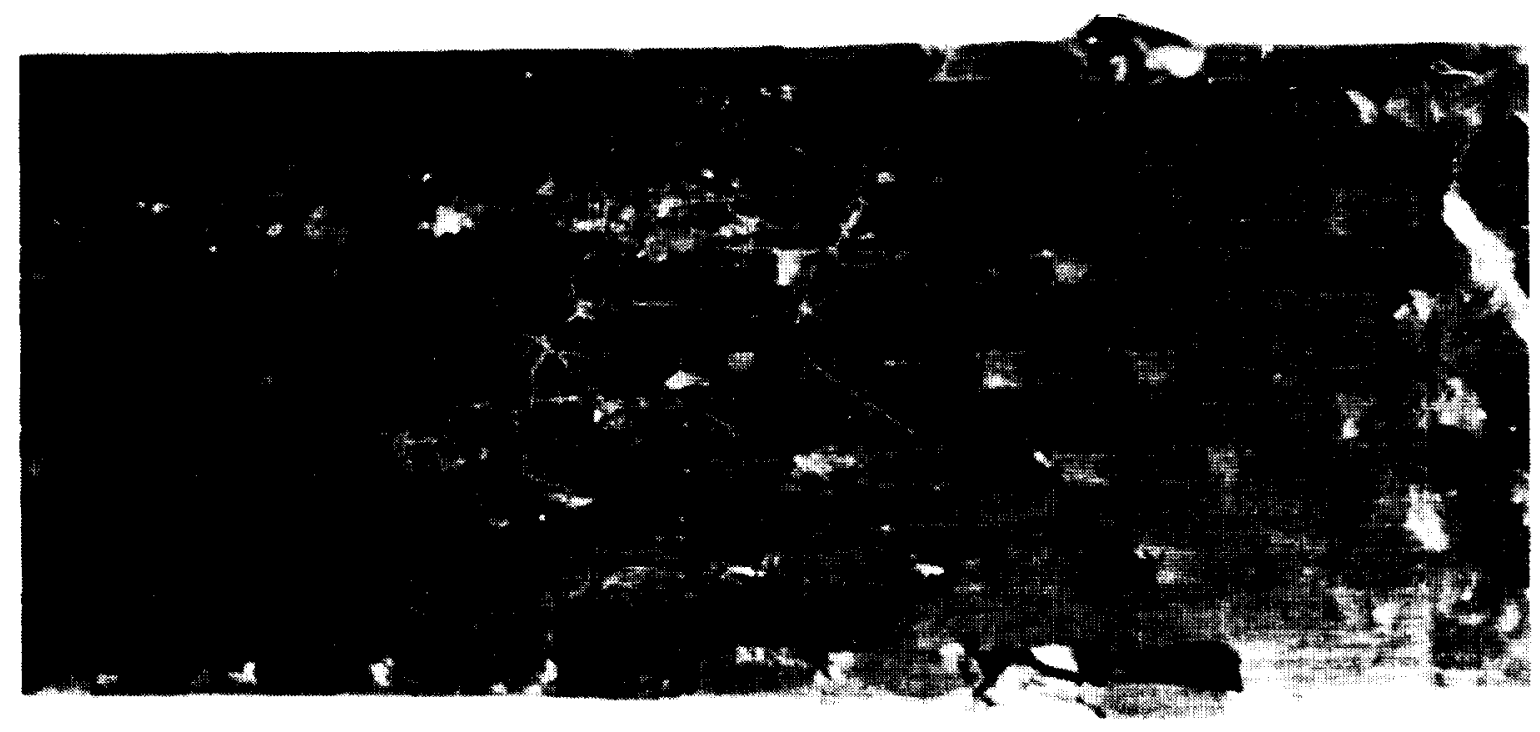

Figure 12. $90^{\circ}$ cross-sectional view of a $0^{\circ}$ uniform failed specimen. Failure progresses along the 45 degree through thickness tows. 


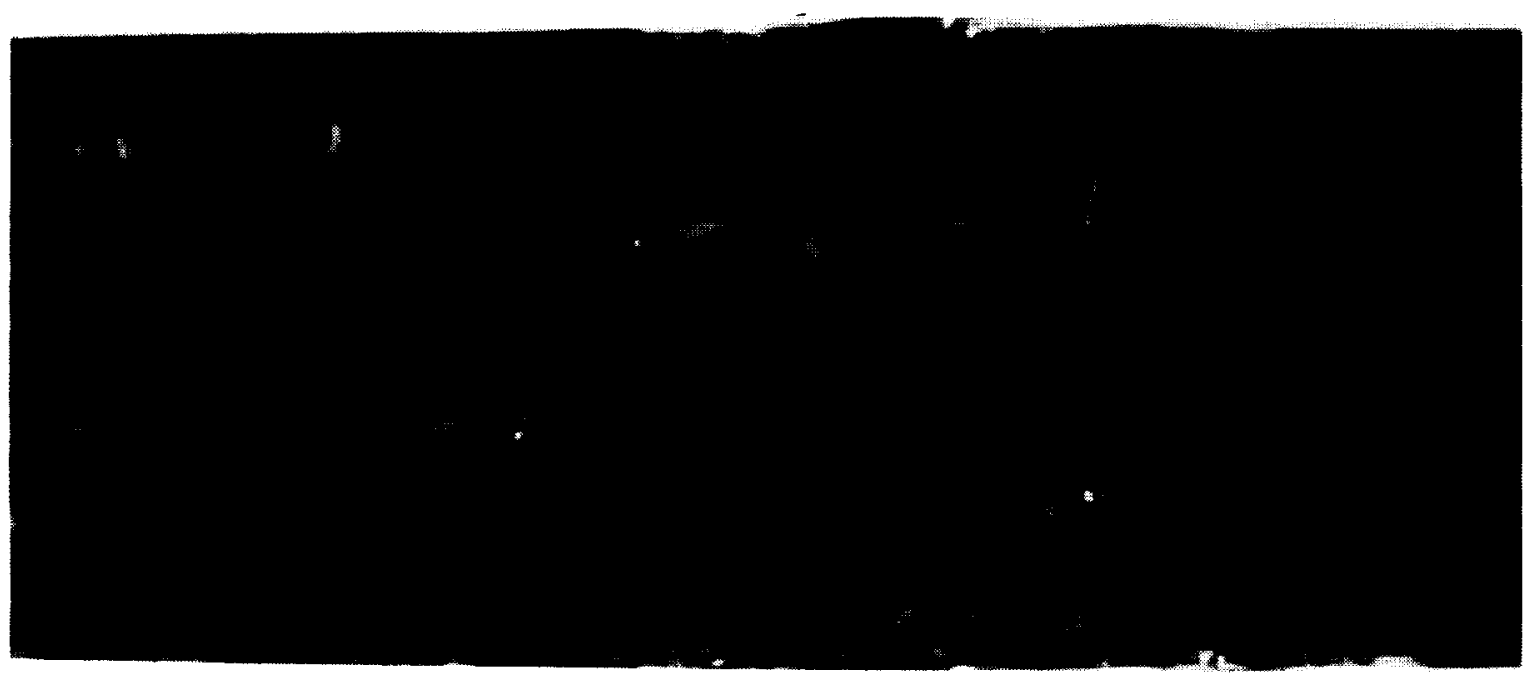

Figure $13.0^{\circ}$ cross-sectional view of a $90^{\circ}$ nonuniform failed specimen. Failure progresses through the thickness perpendicular to the load.

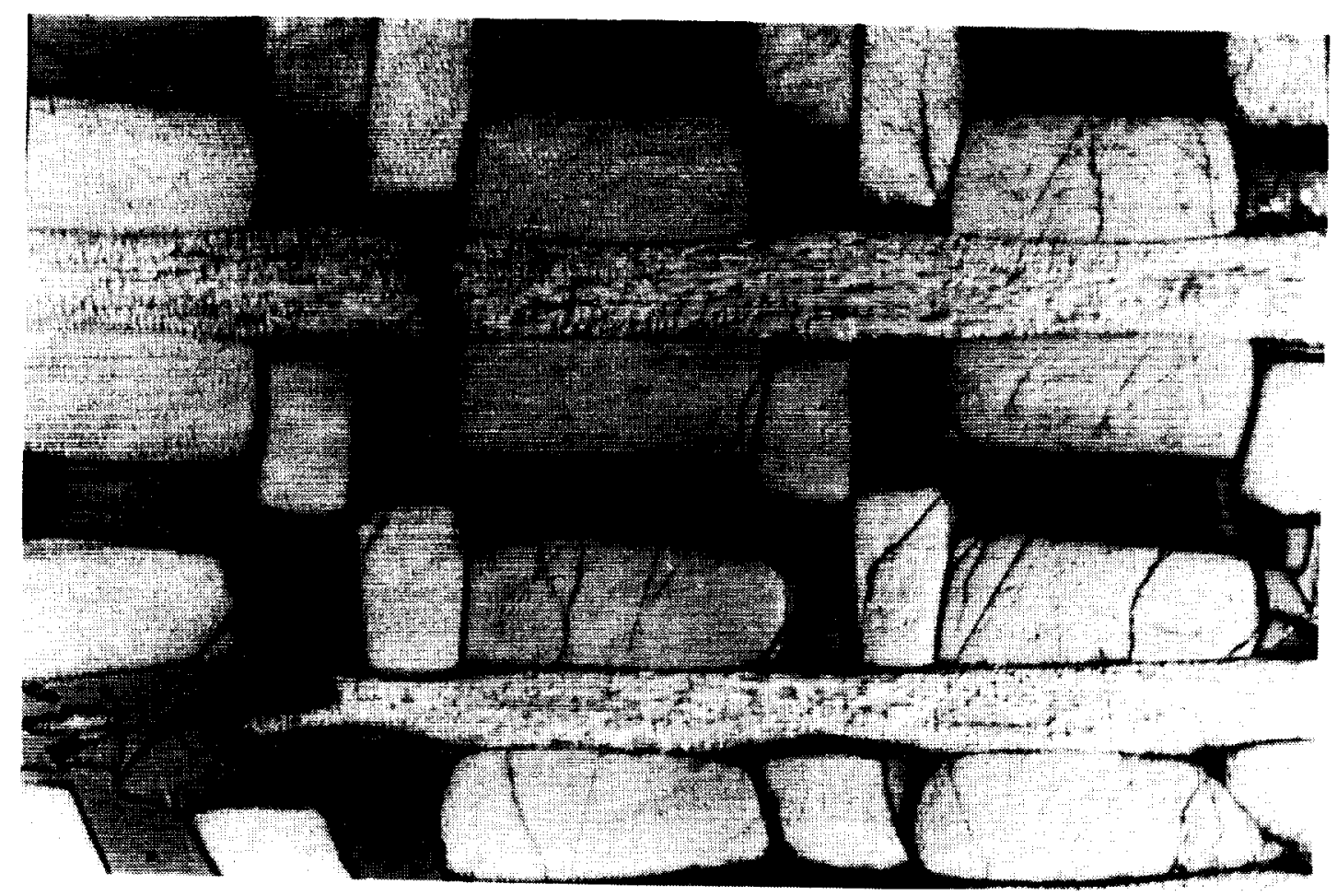

Figure 14. $0^{\circ}$ cross-sectional view of a $90^{\circ}$ tensile specimen. The photograph shows significant matrix cracking, fiber-matrix debonding and intra-tow cracking. 


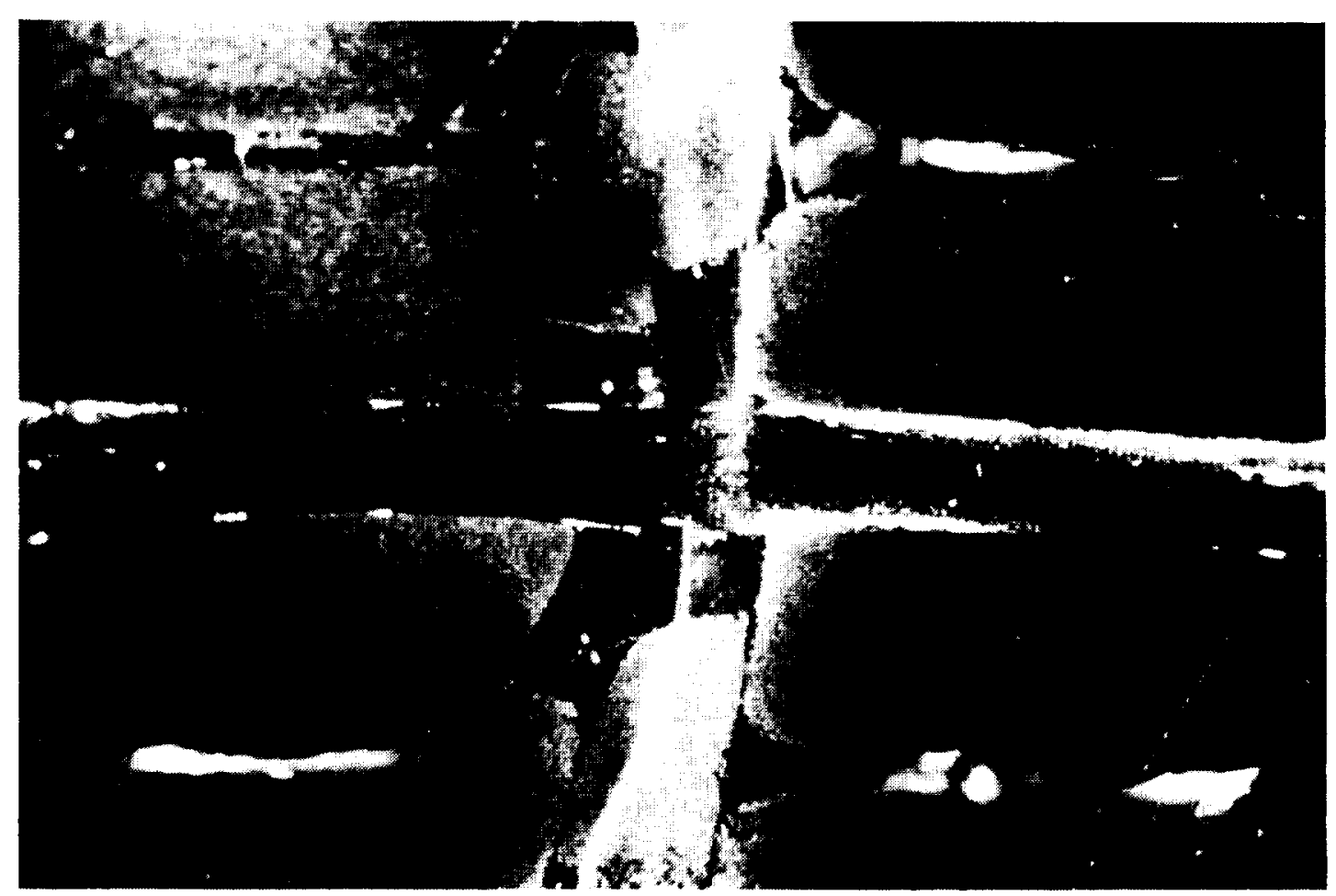

Figure 15. Photomicrograph showing a matrix crack propagating through $90^{\circ}$ and $45^{\circ}$ tows. The photograph also shows fiber debonding.

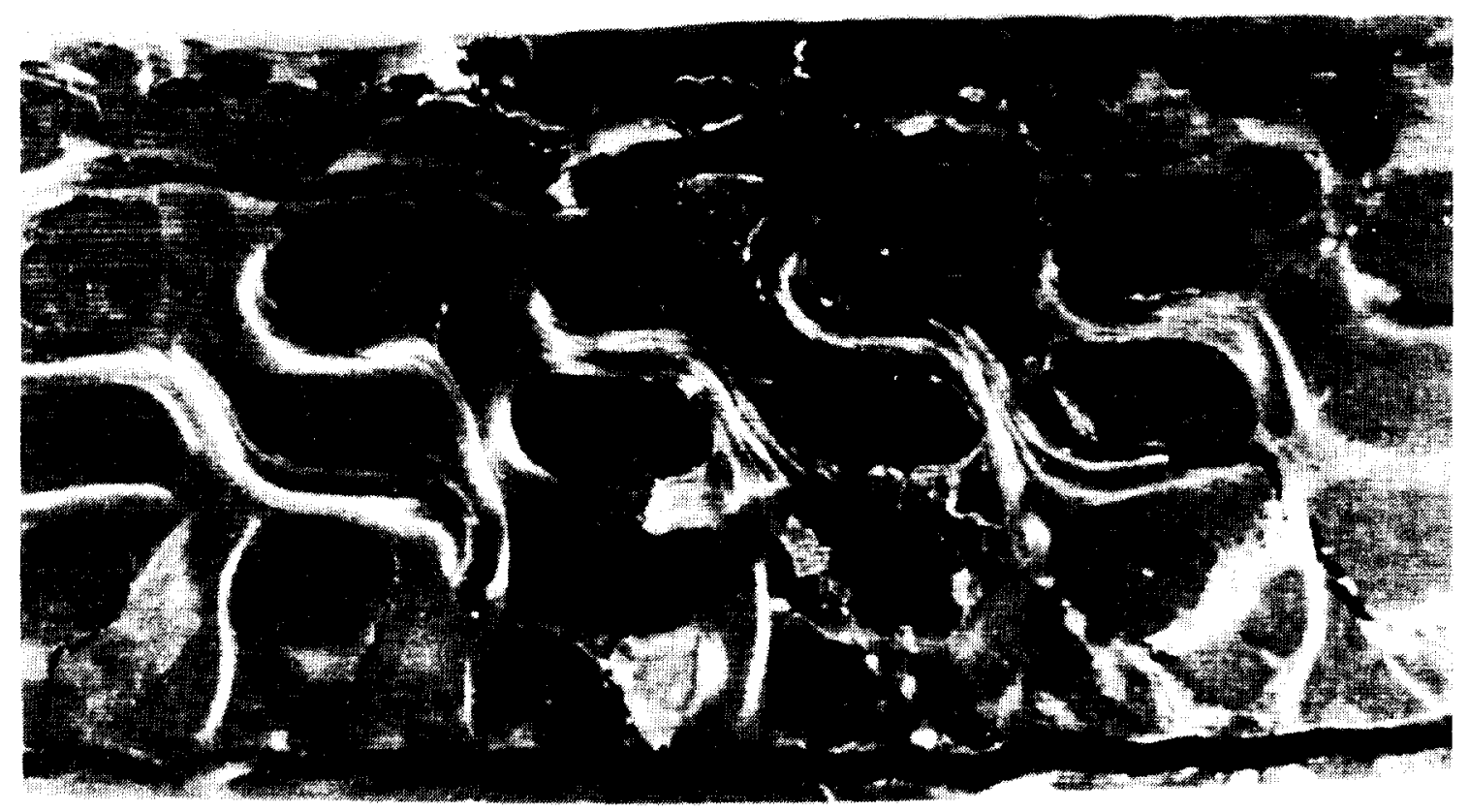

Figure 16. Cracking in a $0^{\circ}$ flexure test specimen. Cracks are seen propagating from the load application point and along the fiber/matrix interface. 
